\title{
Evaluation of Esophageal Motor Function With High-resolution Manometry
}

\author{
Jeffrey L Conklin \\ Division of Digestive Diseases, The David Geffen School of Medicine at UCLA, Los Angeles, CA, USA
}

For several decades esophageal manometry has been the test of choice to evaluate disorders of esophageal motor function. The recent introduction of high-resolution manometry for the study of esophageal motor function simplified performance of esophageal manometry, and revealed previously unidentified patterns of normal and abnormal esophageal motor function. Presentation of pressure data as color contour plots or esophageal pressure topography led to the development of new tools for analyzing and classifying esophageal motor patterns. The current standard and still developing approach to do this is the Chicago classification. While this methodical approach is improving our diagnosis of esophageal motor disorders, it currently does not address all motor abnormalities. We will explore the Chicago classification and disorders that it does not address.

(J Neurogastroenterol Motil 2013;19:281-294)

Key Words

Esophageal motility disorders; Esophagus; Manometry

\section{Where Did High-resolution Manometry Come From and How Does It Work?}

The reliable evaluation of esophageal and gastrointestinal motor function with manometric techniques became possible in the 1970s when Wyle Jerry Dodds and Ron Arndorfer developed the first high-fidelity manometry system. ${ }^{1,2}$ Except for a few technical modifications their approach remained the state-of-the art for 2 decades. In the 1990s, Ray Clouse and his colleagues gave birth to high-resolution manometry (HRM) when they decreased the spacing between pressure sensing sites along the manometry catheter from $3-5 \mathrm{~cm}$ to $1 \mathrm{~cm}$, increased the number of pressure sensors and lengthened the sensing segment of the catheter so it spanned from the pharynx to the stomach. At last it was possible to simultaneously see motor function of the upper esophageal sphincter (UES), esophagus and lower esophageal sphincter (LES) with each swallow, giving us a complete spatial and temporal depiction of esophageal motor function for the first time. ${ }^{3,4}$ The true genius of his method was to convert the pressure data into a topographical plot. The convention at the time was to display manometry recordings in a 2-dimensional (2-D) space with pressure waves stacked sequentially from caudad to cephalad in the y-axis (Fig. 1A). Dr. Clouse and his colleagues added a $z$-axis, and stacked the pressure waves sequentially in the z-axis with gastric pressures to the front and pharyngeal pressures in the

Received: April 12, 2013 Revised: May 9, 2013 Accepted: May 20, 2013

(c) This is an Open Access article distributed under the terms of the Creative Commons Attribution Non-Commercial License (http://creativecommons. org/licenses/by-nc/3.0) which permits unrestricted non-commercial use, distribution, and reproduction in any medium, provided the original work is properly cited.

*Correspondence: Jeffrey L Conklin, MD, FACG

Division of Digestive Diseases, The David Geffen School of Medicine at UCLA, 200 UCLA Medical Plaza 370-8, Los Angeles, CA 90095, USA

Tel: +1-310-467-4078, Fax: +1-310-208-3788, E-mail: jconklin@mednet.ucla.edu

Financial support: None.

Conflicts of interest: Consultant for Given Imaging. 
A

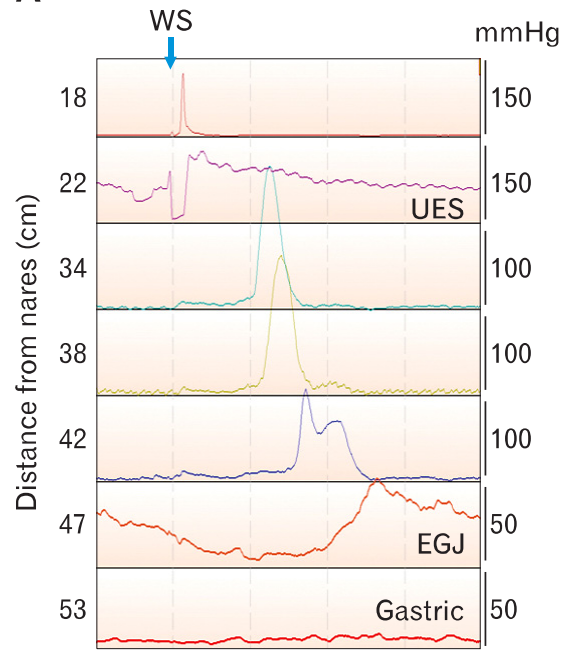

B

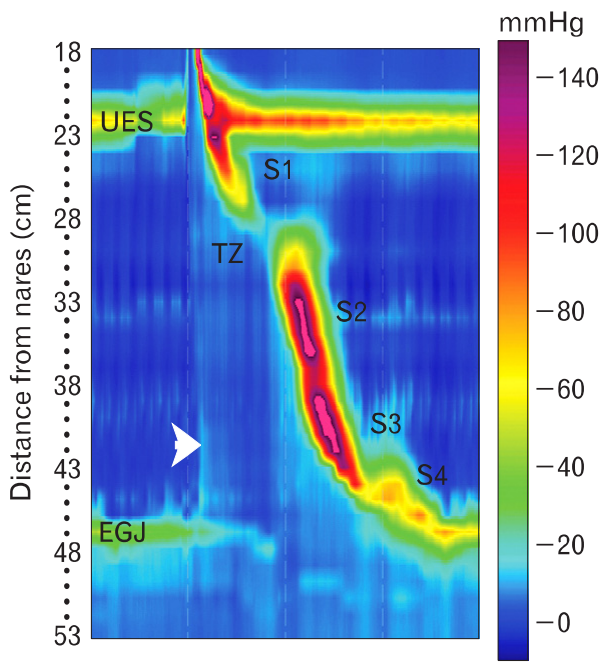

Figure 1. Comparing conventional recordings of manometric pressure with the Clouse plot or esophageal pressure topography (EPT). Conventional manometry tracings came from catheters made with pressure sensors spaced at relatively widely intervals, usually at 3- to 5 -cm. The recording on the left (A) was made with a high-resolution manometry catheter and recording system, but it is displayed in the line mode so it looks like a conventional esophageal manometry recording. Seven of 36 recording channels were chosen for display to mimic what is seen with conventional manometry systems. Channels were selected to record simultaneously from the pharynx to the stomach. With old conventional manometry systems we could not simultaneously view pressures generated by the entire esophagus, including its sphincters. Notice that pressure is on the $y$-axis and time is on the $\mathrm{x}$-axis. The numbers on the left indicate sensor location from the nares. EGJ indicates the esophagogastric junction, and WS indicates the timing of a wet swallow. The figure to the right (B) is esophageal motor activity from the same wet swallow displayed in the color contour mode. In this mode, pressure is represented by color (color bar on the right), sensor location is on the y-axis, and time is on the $\mathrm{x}$-axis. Resting upper esophageal sphincter (UES) and lower esophageal sphincter (LES) pressures are seen horizontal bands of color that are several centimeters wide. Their hues indicate pressures that are greater than in the adjacent pharynx, esophagus, or stomach. Opening of the UES and LES relaxation are depicted as changes of color to hues that represent a lower pressure. A diagonal band of color running from the UES to the LES represents the peristaltic pressure wave. Variations in peristaltic pressure are produced by overlapping esophageal contractile segments: S1 is the striated muscle esophagus, S2 and 3 are the proximal and distal smooth muscle esophagus, respectively, and S4 is the LES repositioning itself at its resting position. There is a pressure trough between S1 and S2 that is called the transition zone, because it is the region over which the esophageal musculature transitions from striated to smooth muscle. Pressure in the swallowed bolus (intrabolus pressure) is represented by a small simultaneous rise in intraesophageal pressure seen as a simultaneous change to a lighter blue color (arrowhead). Notice that when the peristaltic wave passes the color becomes a darker blue indicating bolus clearance. TZ, transition zone.

back. Amplitude was now on the $\mathrm{y}$-axis and time on the $\mathrm{x}$-axis. They developed an interpolation technique that filled in pressure data between pressure waves to give a 3-D pressure contour. They then assigned colors to pressures, with high pressures represented by warmer colors (reds and yellows) and low pressures by cool colors (blues and greens). Finally, they collapsed the color contour back into a 2-D space with time on the $\mathrm{x}$-axis, position relative to the nares on the $y$-axis and pressure depicted as color. This is a color topographical map of esophageal pressure that has been called the Clouse plot or esophageal pressure topography (EPT) (Fig. 1B). In concept, it is like topographical maps of terrain, or weather radar images that assign color to rain intensity. Once one is comfortable with what the EPT means, it is apparent that many motor disturbances are recognizable as distinct patterns. These tools, as will be seen later, have changed how we categorize and define esophageal motor disorders.

\section{How Is It Done With a High-resolution Manometry Set Up?}

The performance of conventional esophageal manometry has been covered in previous reviews, ${ }^{5,6}$ so we will focus on how HRM changed our performance of the study. When positioned appropriately, the HRM catheter's sensing segment spans from the pharynx to the stomach, so that a pressure profile of the entire esophagus and its sphincters can be viewed simultaneously in real time. This makes it easy to identify and characterize anatomical landmarks like the UES and LES. The procedure is simplified greatly, is more tolerable for patients and shortens the time required for data acquisition. These advantages are primarily be- 
cause the pull-through maneuver is not needed to evaluate resting pressures at the esophagogastric junction (EGJ), and the catheter does not have to be repositioned to evaluate various regions of the esophagus.

After the catheter is positioned so that resting pressures generated by the UES and LES are identified, the patient is allowed to accommodate to the catheter. Not doing so leads to artificial elevations of resting UES pressure, and frequently the amplitude and duration of peristaltic contractions in the striated muscle esophagus. In addition, the patient might be unable to stifle dry swallows making it impossible accurately evaluate LES and esophageal motor function. Once the patient accommodates to the catheter, the study is started. The standard esophageal manometry protocol starts with a 30 second baseline recording during which no swallowing occurs, so that resting characteristics of the UES and EGJ (LES and diaphragm) can be determined. This is followed by a series of at least ten, $5 \mathrm{~mL}$ water swallows given in the supine position. This is the protocol used to develop the Chicago classification for evaluating esophageal motor function, which we will discuss later. ${ }^{7}$ A 20-30 second time interval should be allowed to elapse between swallows, so resting LES pressure returns to baseline, and deglutitve inhibition does not hinder esophageal motor function. ${ }^{8}$ If a dry swallow occurs during the 20-30 second interswallow interval, time to the next wet swallow must be reset.

Several investigators have deviated from the standard esophageal manometry protocol. If the HRM catheter has solid-state sensors, the manometry can be performed with the patient either seated or upright. Normal values are available for both situations. ${ }^{9,10}$ There are times when challenging the esophagus helps make the diagnosis. For example, sometimes a patient will complain of dysphagia or chest discomfort only with solid foods, but 5 $\mathrm{mL}$ water swallows produce neither symptoms nor significant esophageal motor dysfunction. In such a situation, challenging the esophagus to work harder with viscous (e.g., applesauce), solid boluses (e.g., cubed bread or marshmallow) or multiple water swallows can uncover esophageal motor disorders not seen with 5 $\mathrm{mL}$ water swallows, and improve the correlation of symptoms with esophageal motor disturbance. ${ }^{11-15}$

\section{How Is the Study Analyzed?}

Analysis of manometric data describes resting characteristics of the esophageal sphincters, and esophageal motor functions initiated by swallowing. For the most part, this analysis is an auto- mated process carried out by software algorithms. Unfortunately, these computerized analysis packages are far from perfect, allowing erroneous diagnoses to be made if the person reading the study does not remain engaged in the process and interact with the software. In practice, the clinician must review each swallow to be sure that measurement parameters and anatomical landmarks are appropriately identified.

Usually, the analysis starts by evaluating the resting characteristics of the esophageal sphincters during a 30 -second period when no swallowing occurred. The UES and LES are easily identified as zones of higher pressure that are depicted in the EPT as horizontal bands of color. Variations in pressure produced by respiration are seen as cyclical changes in color. Esophageal pressure topography allows a more detailed analysis of the EGJ than does conventional manometry. Resting LES pressure is distinguished from diaphragmatic crural contraction, and the pressure inversion point (PIP) can be identified (Fig. 2). The PIP is the location along the vertical axis of the recording segment at which the more negative intrathoracic pressure produced by inspiration inverts to a more positive intragastric pressure. The PIP basically identifies where the diaphragm partitions the chest from the abdomen. Spatial separation of the PIP from pressure produced by a resting LES identifies a hiatal hernia (Fig. 2). ${ }^{16}$ By convention resting LES pressure is the respiratory minimum LES pressure; that is, the mean of the lowest EGJ pressures during expirations in the 30 -second period when no swallowing occurred. This excludes pressures produced by diaphragmatic crural contraction, and is thought to more faithfully reflect true resting LES pressure.

The next step is to evaluate esophageal motor function resulting from water swallows (Fig. 1B). The normal EPT produced by swallowing is characterized by opening of the UES and EGJ, which are portrayed as changes in color to hues representing lower pressures: UES pressure/color approximates that in the proximal esophagus, and LES pressure/color approximates that in the stomach (Fig. 1). Esophageal peristalsis is seen in the EPT as a series of 4 overlapping segmental contractions running diagonally from the UES to EGJ (Fig. 1B).,

The EPT provides a much richer data set than conventional manometry. This led to the development of a still evolving group of tools to analyze the EPT, the Chicago classification. It should be noted that the Chicago classification was derived using the ManoScan $^{\text {TM }}$ (Sierra Scientific Instruments, Los Angeles, CA, USA) HRM system, and normative data from other HRM systems may vary somewhat from this. 


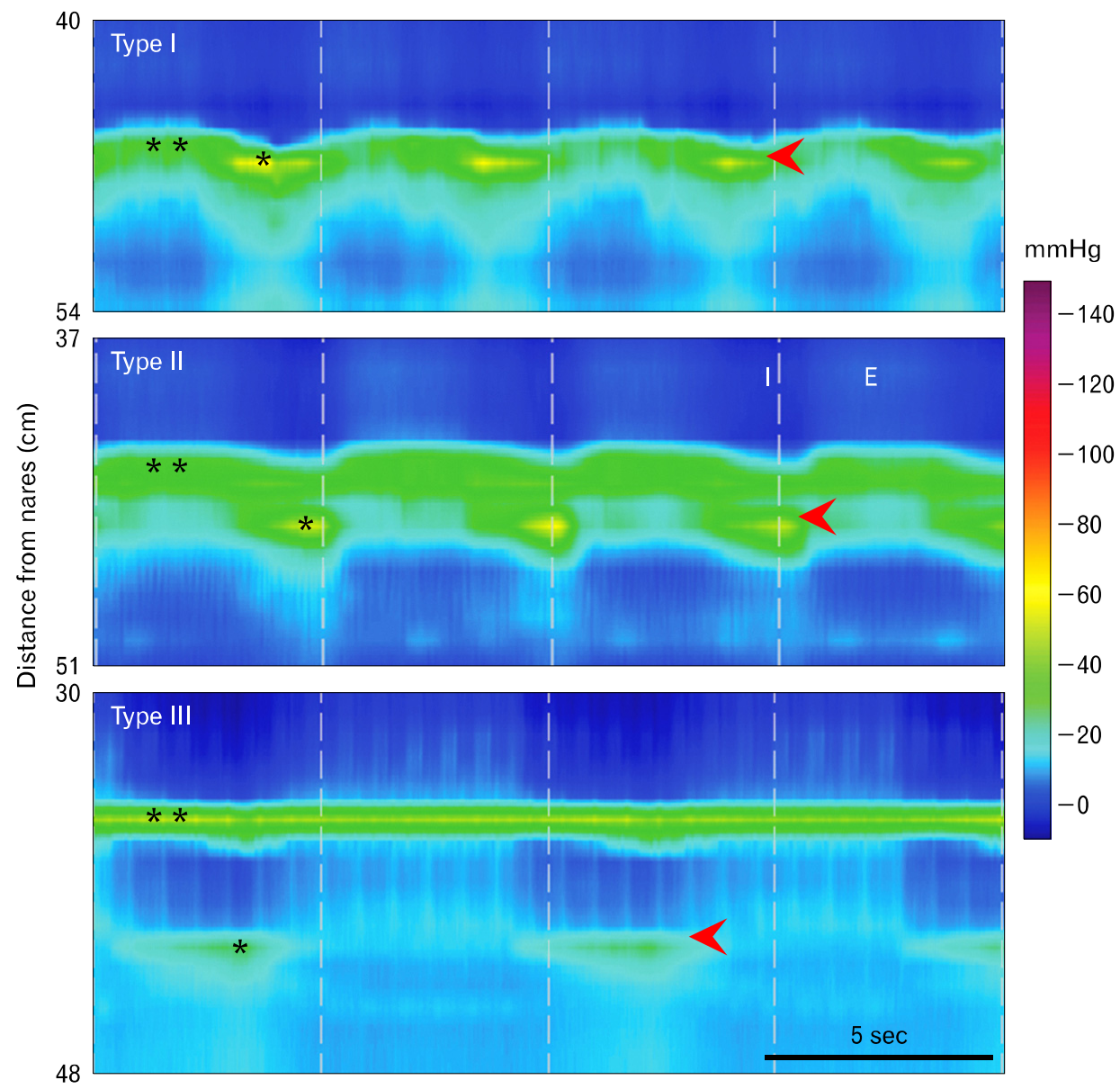

Figure 2. The esophagogastric junction at rest. Pressures recorded from the esophagogastric junction (EGJ) are a composite of tonic lower esophageal sphincter (LES) contraction $(* *)$ and cyclical crural diaphragm contraction with inspiration $(*)$. During inspiration pressure decreases in the thoracic cavity, and during expiration it increases. The opposite is true in the abdominal cavity. The point at which pressure across the EGJ during inspiration becomes negative relative to intrabdominal pressure is called the respiratory or pressure inversion point (PIP). It indicates the location of the crural diaphragm. The red arrowhead denotes the location of the PIP. The top panel is an example of a normal (Type I) EGJ in which the LES and crural diaphragm are coincident. In the middle panel there is a small spatial separation $(<2 \mathrm{~cm})$ of the diaphragm from the LES, indicating a small hiatal hernia (Type II EGJ). In the bottom panel there is a large spatial separation $(>2 \mathrm{~cm})$ between the crural diaphragm and LES, indicating the presence of a large hiatal hernia (Type III EGJ). I, inspiration; E, expiration.

The first step in the classification process is to evaluate EGJ anatomy and function. "Was the catheter passed across the LES and hiatus?" When properly placed, the PIP is apparent. Failure to adequately place the catheter compromises further analysis because no data can be obtained regarding the EGJ. "Is there a hiatal hernia?" Hiatal hernia is discerned in the EPT as a separation of the LES and crural diaphragm (Fig. 2). "What is the resting LES pressure?" While resting LES pressure is not used in the Chicago classification, a hypertensive LES might be a clue to dysfunction of inhibitory motor neurons supplying the LES and a harbinger of future spastic motor dysfunction. "Does the EGJ relax normally with swallowing?" Stated another way is there ab- normal resistance to bolus movement across the EGJ? A tool called the integrated relaxation or residual pressure (IRP) was developed to address this issue (Fig. 3). ${ }^{16}$ To determine the IRP, a computer algorithm first detects the upper and lower margins of the EGJ, and then identifies a 10-second time window that begins at the start of UES relaxation initiated by swallowing. A tool called the eSleeve (Sierra Scientific Instruments, Los Angeles, CA, USA), which measures pressure simultaneously over a $6 \mathrm{~cm}$ length, is positioned to straddle the LES. It calculates maximum pressure along the $6 \mathrm{~cm}$ segment at each time point within the 10-second time window. The 4-second IRP algorithm takes these pressures and averages the lowest of them, the nadir pres- 


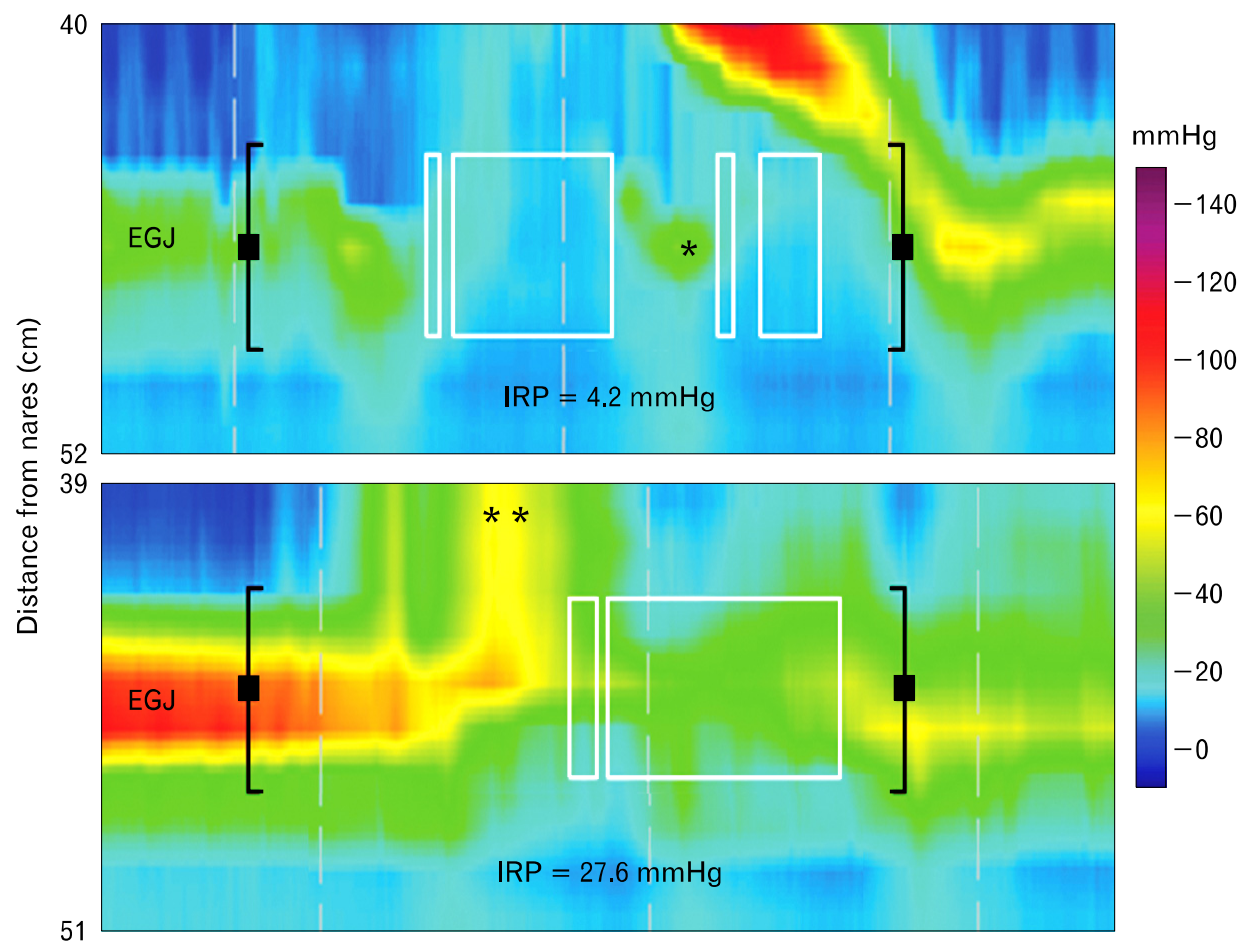

Figure 3. Evaluation of esophagogastric junction (EGJ) function during swallowing. The top panel is an esophageal pressure topography (EPT) of normal EGJ function following a wet swallow. As you can see pressure at the EGJ normally drops ahead of the advancing peristaltic pressure wave. It is not a direct measure of lower esophageal sphincter (LES) relaxation, but pressure in the swallowed bolus as it opens and traverses the EGJ. Esophagogastric junction function during swallowing is determined by a measurement called the 4-second integrated relaxation (residual) pressure (IRP). It is determined within a "deglutitive relaxation window," a window that straddles the EGJ and stretches for 10 seconds after opening of the upper esophageal sphincter (UES) (black brackets). This is the spatial and temporal domain within which EGJ function is evaluated. A tool called the $\mathrm{eSleeve}^{\mathrm{TM}}$ is used to set the spatial extent of the window, which is $6 \mathrm{~cm}$ in length by default. The eSleeve determines the highest pressure within the deglutitve relaxation window at each point in time. The 4-second IRP algorithm takes these pressures and averages the lowest of them over four continuous or discontinuous seconds (white boxes). This discontinuous measurement avoids inclusion of elevated pressures produced by contraction of the crural diaphragm (*) or cardiovascular structures in the calculation of IRP. The lower panel is an example of an abnormal IRP seen in achalasia. In this case, pressure at the EGJ results from failed LES relaxation and pressurization of the swallowed bolus above the LES (**).

sure, over 4 continuous or discontinuous seconds. Using 4 discontinuous seconds to determining nadir pressure eliminates cardiovascular artifacts, and pressures produced by contraction of the crural diaphragm during inspiration from calculation of the IRP. According to the Chicago classification, the upper limit of normal for IRP is $15 \mathrm{mmHg}$ (Fig. 3). ${ }^{17}$ Any pathological process, mechanical or functional, that impedes flow across the EGJ, can elevate the IRP. Some of these abnormalities include achalasia, neoplasms or strictures at the EGJ, and surgical misadventures related to Nissen fundoplication or laparoscopic band.

After evaluating EGJ function, the classification scheme turns to evaluation of esophageal motor function. The first step in this evaluation is to determine "peristaltic integrity" is peristalsis present and if so is it a continuous process? To determine peristaltic integrity, a $20 \mathrm{mmHg}$ isobaric contour line is applied to the
EPT. It appears as a black line over all parts of the EPT where the pressure is $20 \mathrm{mmHg}$, and identifies if pressure drops below $20 \mathrm{mmHg}$ during the peristaltic pressure wave (Fig. 4 and 5). A threshold value of $20 \mathrm{mmHg}$ above which intact esophageal peristalsis is defined was chosen because this is the peristaltic pressure required for normal bolus transit when the EGJ is functioning normally. Peristaltic integrity is assessed by measuring gaps in the $20 \mathrm{mmHg}$ contour along the length of the esophagus, between the UES and LES (Fig. 5). According to the Chicago classification small defects measure $2-5 \mathrm{~cm}$ and large defects are $>5 \mathrm{~cm}$.

There are 2 measures to evaluate propagation of esophageal pressure waves; the "contraction front velocity (CFV)" and the "distal latency (DL)" (Fig. 4). The CFV is a measure of peristaltic velocity in the smooth muscle esophagus; that is, from the 


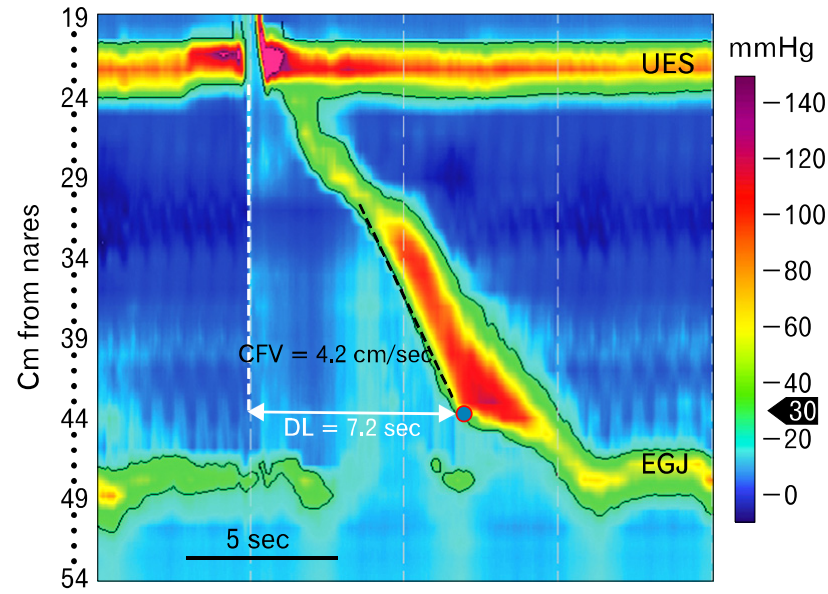

Figure 4. Contraction front velocity (CFV) and distal latency are tools used to evaluate propagation of esophageal pressure waves. This figure depicts normal function of the esophagus and its sphincters. The black line is a $30 \mathrm{mmHg}$ isobaric contour line. It identifies all loci in the esophageal pressure topography (EPT) where the pressure is $30 \mathrm{mmHg}$. The red circle filled with blue indicates the contractile deceleration point (CDP), which is the time point during a peristaltic pressure wave when peristalsis in the distal esophagus appears to slow appreciably. Functionally the CDP is the time at which esophageal peristalsis terminates, and the lower esophageal sphincter descends to its resting position in association with emptying of the phrenic ampulla. The CFV, which is a measure of peristaltic velocity in the smooth muscle esophagus, is obtained by calculating velocity from a best linear fit along the 30 $\mathrm{mmHg}$ contour line at the leading edge of the peristaltic pressure wave from transition zone to CDP (black dashed line). The other measure of propagation is the distal latency. It is the time from opening of the upper esophageal sphincter during swallowing (dashed white line) to the CDP. DL, distal latency; UES, upper esophageal sphincter; EGJ, esophagogastric junction.

distal extent of the transition zone to a landmark called the "contractile deceleration point (CDP)" (Fig. 4). ${ }^{18}$ The CDP is the time point during a peristaltic pressure wave at which peristalsis in the distal esophagus appears to slow appreciably. Functionally the CDP is the time at which esophageal peristalsis terminates, and the LES begins to descend to its resting position. Descent of the LES is seen radiographically as emptying of the phrenic ampulla. The CFV is obtained by calculating velocity from a best linear fit along the $30 \mathrm{mmHg}$ isobaric contour line at the leading edge of the peristaltic pressure wave from transition zone to CDP (Fig. 4). The CFV can appear rapid when the bolus is pressurized between an unyielding EGJ and a peristaltic contraction (Fig. 6). This situation might be mistaken by automated analysis software as a simultaneous contraction. The circumstance can be remedied by choosing an isobaric contour pressure that ex-

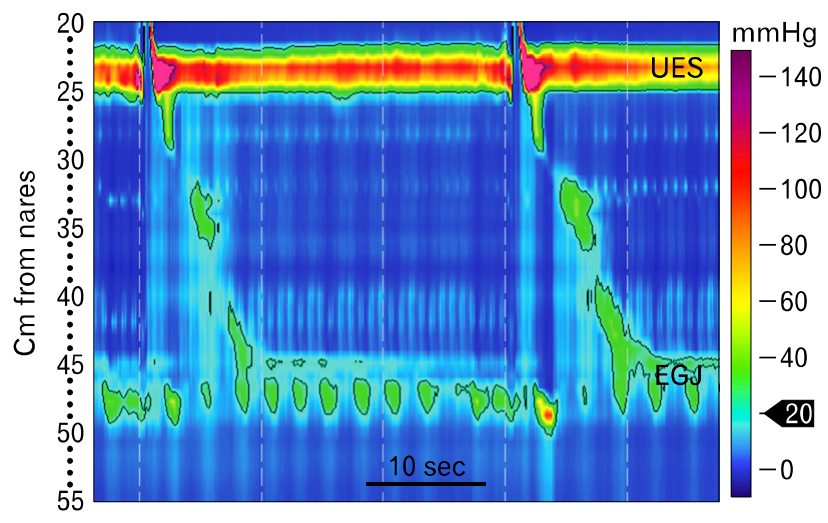

Figure 5. Weak peristalsis is like ineffective esophageal motor function described by conventional manometry. The black line is the $20 \mathrm{mmHg}$ isobaric pressure line. Weak peristalsis is characterized by gaps in the 20 $\mathrm{mmHg}$ isobaric pressure contour in the smooth muscle esophagus, or a wide transition zone. UES, upper esophageal sphincter.

ceeds pressure at the EGJ. The normal CFV does not exceed 9 $\mathrm{cm} /$ sec. $^{18}$

The distal latency is not a measure of peristaltic contraction velocity. Instead, it identifies the time from the start of swallow induced UES opening to arrival of esophageal contraction at the CDP. ${ }^{19}$ It is presumed to measure post deglititive inhibition and adequacy of inhibitory neuromuscular function in the smooth muscle esophagus. ${ }^{20,21} \mathrm{~A}$ short DL indicates early arrival the esophageal contraction in the distal esophagus. It is now used instead of rapid CFV in the Chicago classification to diagnose distal esophageal spasm because it more reliably identifies patients with this disorder. ${ }^{22}$ The lower limit of normal for DL is 4.5 seconds. ${ }^{19}$

The rich detail inherent to the EPT allowed development of a tool called the distal contractile integral (DCI), which is used to measure the robustness of peristaltic contraction in the smooth muscle esophagus (Fig. 7). Unlike conventional manometry, which uses contraction amplitude for this purpose, the DCI integrates pressure, distance and time along the esophagus. ${ }^{22}$ The analysis is performed by making a box that encompasses all swallow induced motor activity produced by contractile segments S2 and S3 (Fig. 7). The DCI is calculated by summing pressures $>$ $20 \mathrm{mmHg}$ from all of the time/length foci within the box. Said another way, it is basically an aggregate of the mean contraction amplitude of the smooth muscle esophagus, the length over which that contraction propagates, and duration of contraction. It was derived from a study of manometries done on 75 asymptomatic controls and 400 patients. ${ }^{23}$ The investigators observed that the DCI was $<5,000 \mathrm{mmHg} \cdot \mathrm{cm} \cdot \mathrm{sec}$ in all 75 asymptomatic controls and $<8,000 \mathrm{mmHg} \cdot \mathrm{cm} \cdot \mathrm{sec}$ in all asymptomatic 


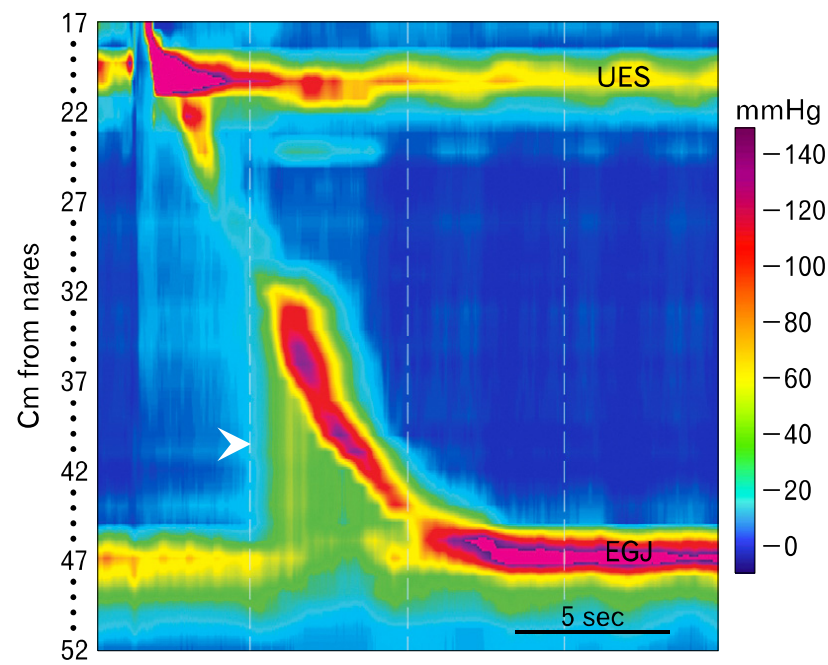

Figure 6. Esophagogastric junction (EGJ) outflow obstruction is characterized by failed or incomplete opening of the EGJ (integrated relaxation or residual pressure [IRP] greater than normal), some peristalsis in the smooth muscle esophagus and pressurization of the swallowed bolus between an unyielding EGJ and peristaltic contraction (arrowhead). Peristalsis can be normal, weak, hypertensive or hypercontractile. UES, upper esophageal sphincter.

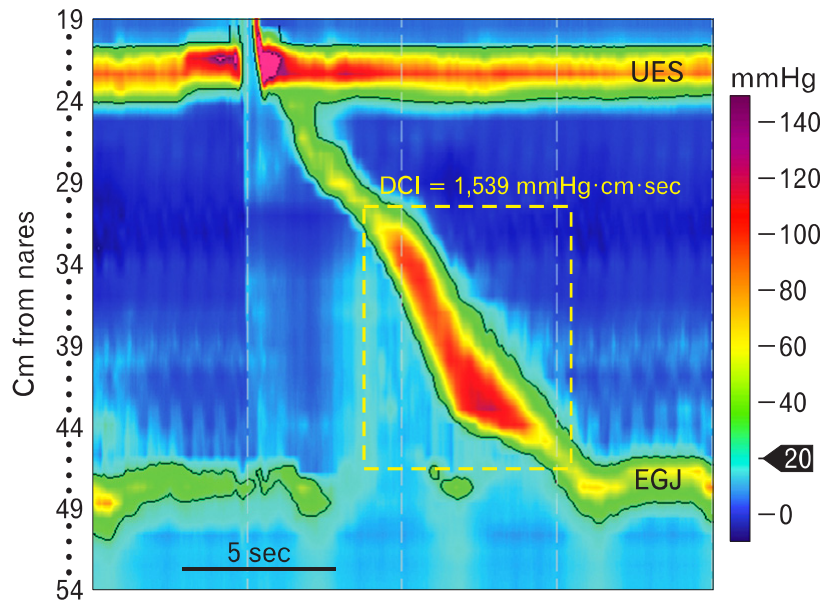

Figure 7. The distal contractile integral (DCI) is a measure of how robust peristalsis is in the smooth muscle esophagus. It is determined by first making a box that encompasses all swallow induced motor activity produced by contractile segments S2 and S3 (yellow dashed line). Next, the $20 \mathrm{mmHg}$ isobaric contour line is determined (black line). The DCI is calculated by summing pressures from all of the time/length foci within the field constrained by the box and $20 \mathrm{mmHg}$ isobaric contour line. UES, upper esophageal sphincter; EGJ, esophagogastric junction.
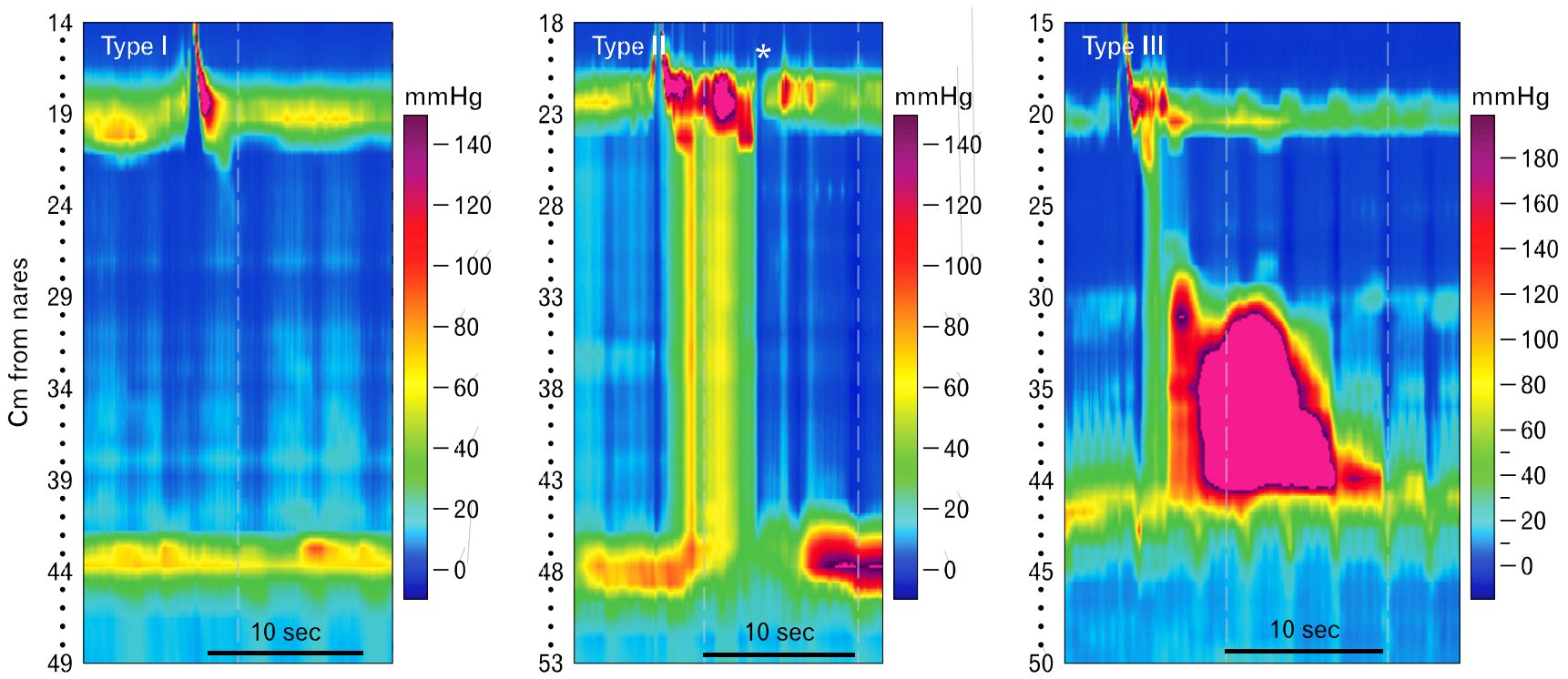

Figure 8. Achalasia is defined by failure of normal peristalsis and an inadequate lower esophageal sphincter relaxation (integrated relaxation or residual pressure [IRP] greater than normal). The disorder is further subclassified based upon the morphology of esophageal pressure patterns. Type I is characterized by little if any discernable pressure activity in the esophagus, type II by panesophageal pressurization and type III by premature esophageal contraction (short distal latency). Transient opening of the UES seen in the middle panel $(*)$ is commonly seen in patients with achalasia and in other esophageal disorders that inhibit bolus clearance. It is not a swallow because no pharyngeal peristalsis is seen in conjunction with it. Instead it represents a venting mechanism.

patients. The $20 \mathrm{mmHg}$ limit is used to avoid including intrabolus pressure or pressure produced by vascular structures in the calculation of DCI.
The third step in analyzing the EPT according the Chicago classification is to determine if there is a pressurization pattern, which can be useful in understanding the pathogenesis of some 
esophageal motor disorders. Pressurization is easily recognized as isobaric pressure (consistent pressure) along varying lengths of the esophagus. ${ }^{16,23}$ It indicates bolus entrapment, often between an esophageal contraction and a mechanical or functional obstruction, usually at the EGJ (Fig. 6). This pattern is seen with esophageal strictures or neoplasms, Nissen fundoplications and lap bands, and is sometimes a variant of achalasia. Panesophageal pressurization; that is, an isobaric pressure that spans from the UES to EGJ, is one of the common features of achalasia. Its presence defines type II achalasia (Fig. 8). ${ }^{24,25}$

After all of the swallows are analyzed with the tools described above, the data are used in the Chicago classification to make a diagnosis. The way this is done is seen in Figure 9. First the adequacy of LES function is determined (upper left), and then esophageal motor function is characterized. There are 4 general groupings of esophageal motor abnormality: achalasia, esophageal outlet obstruction, abnormalities of esophageal motor function not seen in normal people and borderline abnormalities of esophageal function that, while not classified as normal, are commonly seen in asymptomatic individuals.

"Achalasia" is clinically and pathophysiologically the best understood of esophageal motor disorders. It has been for many years defined by conventional manometry as failure of LES relaxation and absence of peristalsis in the smooth muscle esophagus. With the introduction of HRM the diagnosis has been dissected a bit more finely into 3 types, ${ }^{24}$ all of which are characterized by failure of LES relaxation, but have differing esophageal motor patterns (Fig. 8). Type I achalasia has no appreciable esophageal motor activity, type II is characterized by panesophageal pressurization following at least $20 \%$ of wet swallows, and type III exhibits premature contractions with at least $20 \%$ of wet swallows. Exploration of treatment outcomes based upon achalasia type demonstrated that type I is better treated with Heller myotomy than balloon dilation, type II is very responsive to any treatment chosen, and type III has the worst prognosis. ${ }^{24,26}$

"Esophagogastric junction outflow obstruction" is charac-

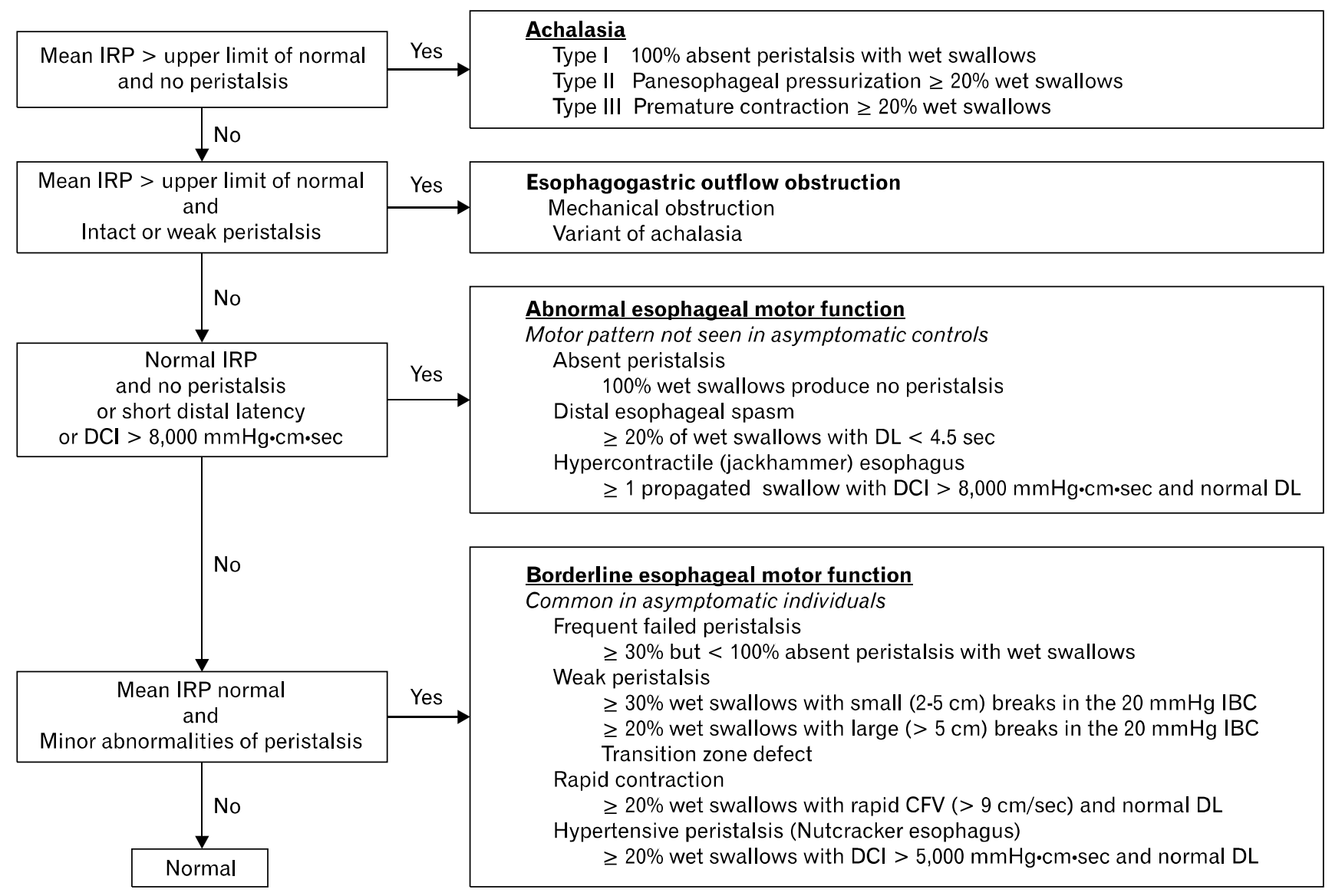

Figure 9. The Chicago classification. ${ }^{29}$ IRP, integrated relaxation or residual pressure; DCI, distal contractile integral; DL, distal latency; $\mathrm{CFV}$, contraction front velocity; IBC, isobaric contour. 
terized by failed or incomplete opening of the EGJ, some peristalsis in the smooth muscle esophagus and pressurization of the swallowed bolus between the unyielding EGJ and peristaltic contraction (Fig. 6). ${ }^{27,28}$ Peristalsis can be normal, weak, hypertensive or hypercontractile. Mechanical barriers (e.g., strictures, neoplasms, tight fundoplications or tight lap bands), can cause outflow obstruction so this pattern should trigger an evaluation with endoscopy and perhaps endoscopic ultrasound. When no mechanical obstruction is found, this EPT pattern might indicate a variant of achalasia, which often responds to achalasia treatment.

The classification of abnormal esophageal motor function is a diverse group of esophageal motor abnormalities that are not seen in asymptomatic individuals. They include absent peristalsis, distal esophageal spasm and jackhammer esophagus.

"Absent peristalsis" is characterized by a normal IRP and no peristalsis in the smooth muscle esophagus. Seeing this pattern should trigger some clinical questions. Does the patient have a collagen vascular disease, particularly scleroderma, diabetes or hypothyroidism? If the patient has symptomatic gastroesophageal reflux disease, which frequently accompanies absent peristalsis, is fundoplication a wise choice?

"Distal esophageal spasm" is an uncommon EPT pattern that is characterized by at least $20 \%$ of wet swallows producing a short DL ( $<4.5$ seconds), and normal IRP (Fig. 10A). This measure was added to the classification scheme because it is better than a rapid CFV (Fig. 10B) as an identifier of esophageal spasm. In one study, patients who responded to wet swallows by generating esophageal contractions with a short DL had symptoms of and were being treated as if they had either esophageal spasm or spastic achalasia, while patients with a rapid CFV were given a variety of diagnoses. ${ }^{19}$

"Jackhammer esophagus" is relatively rare EPT pattern that is defined as $\geq 1$ wet swallow producing a propagated contraction in the smooth muscle with a DCI $>8,000 \mathrm{mmHg} \cdot \mathrm{cm} \cdot \mathrm{sec}$, normal distal latency and normal IRP (Fig. 11). These contractions are usually prolonged and multiphasic. This pattern of contraction is typically associated with dysphagia and/or non-cardiac chest pain, which might be amenable to medications that modulate visceral pain and/or relax smooth muscle. It is occasion-
A

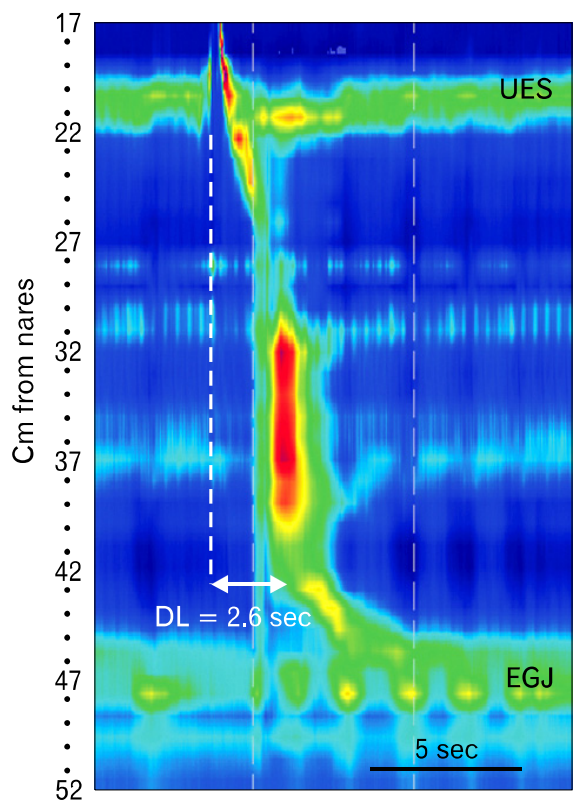

B

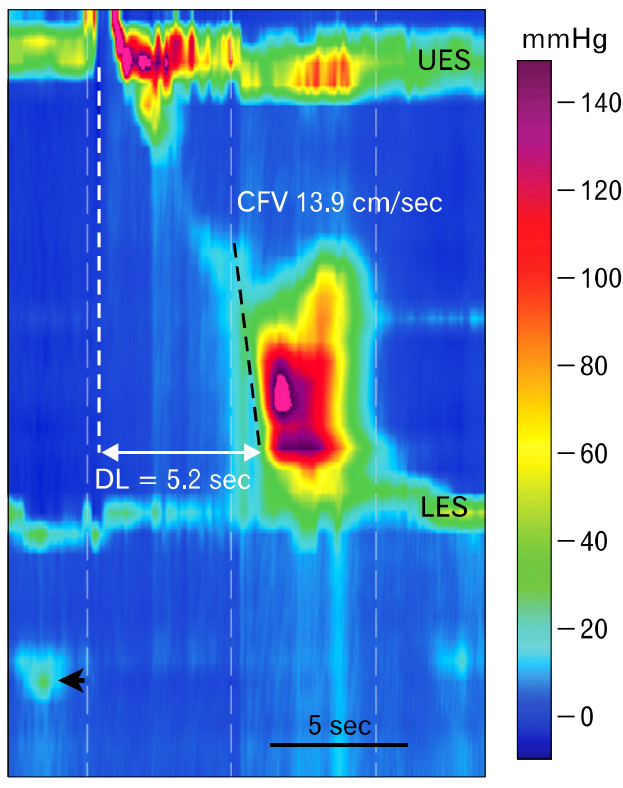

Figure 10. Evaluation of peristalsis with the distal latency and contraction front velocity. (A) Distal esophageal spasm is characterized by normal lower esophageal sphincter relaxation and a short distal latency ( $<4.5$ seconds). It is arrival of the swallow-induced contraction in the distal esophagus too rapidly, producing a simultaneous contraction. (B) Rapid contraction is defined by a rapid contraction front velocity ( $>9 \mathrm{~cm} / \mathrm{sec}$ ), normal distal latency ( $>4.5$ seconds) and normal integrated relaxation or residual pressure. The peristaltic pressure wave also meets criteria for weak peristalsis; that is, a wide gap at the transition zone produced by failure of peristalsis in the proximal smooth muscle esophagus. This might be the genesis of the measured rapid wave front velocity. Finally, the black arrow indicates a diaphragmatic contraction, so there is a large hiatal hernia. DL, distal latency; UES, upper esophageal sphincter; EGJ, esophagogastric junction; CFV, contraction front velocity; LES, lower esophageal sphincter. 


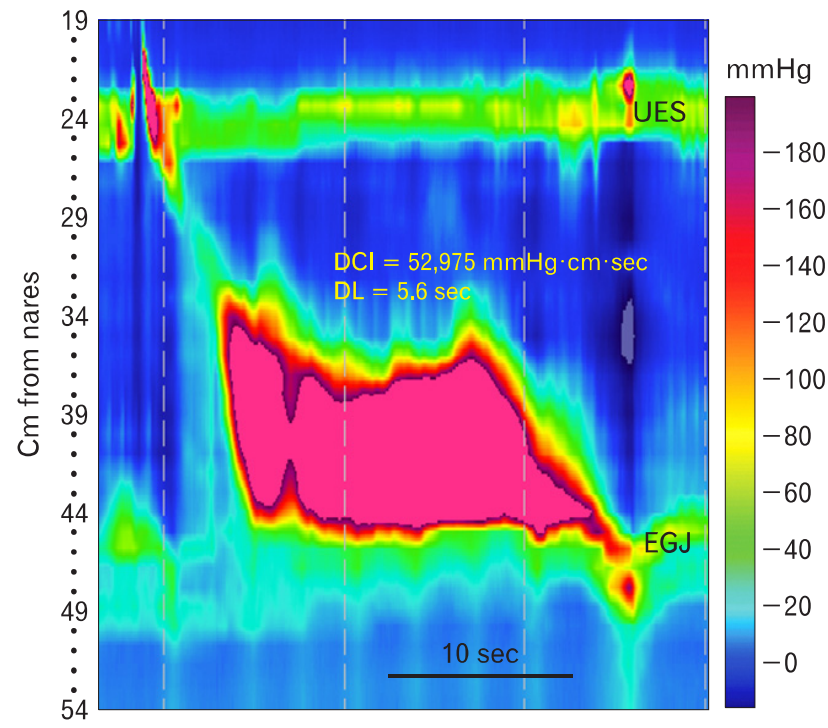

Figure 11. The jackhammer esophagus is characterized by a distal contractile integral of $>8,000 \mathrm{mmHg} \cdot \mathrm{cm} \cdot \mathrm{sec}$, with normal propagation of the peristaltic wave front (distal latency $>4.5$ seconds) and normal integrated relaxation or residual pressure. In the past it was considered part of the spectrum of nutcracker esophagus. DCI, distal contractile integral; DL, distal latency; UES, upper esophageal sphincter; EGJ, esophagogastric junction.

ally associated with the EPT pattern of EGJ outflow obstruction, suggesting that the esophagus is working very hard against an obstruction at the EGJ. This should trigger a search for a lesion obstructing the EGJ. This combination of EPT patterns might also be the initial signs of an inhibitory myenteric neuropathy, and be a harbinger of achalasia to come.

The final category of motor abnormalities in the Chicago classification is called "borderline esophageal motor function". This is a diverse group of motor abnormalities including frequent failed or weak peristalsis, rapid contraction and hypertensive peristalsis. They probably account for the bulk of manometric abnormalities seen in most motility labs. "Weak peristalsis," which is characterized by defects in the $20 \mathrm{mmHg}$ isobaric contour (Fig. 5), and "frequent failed peristalsis" are akin to the ineffective esophageal motor function described with conventional manometry. These motor abnormalities are associated with poor bolus transit and proximal escape, particularly when the gap is at the level of the transition zone. ${ }^{30}$ Patients sometimes sense failed bolus clearance as dysphagia or even regurgitation. Rapid contraction is characterized by $>20 \%$ of wet swallows producing peristalsis with a velocity of $>9 \mathrm{~cm} / \mathrm{sec}$, a normal DL and normal IRP (Fig. 10A). This pattern is not specific for DES, and can be associated with a variety of esophageal disorders including
GERD. "Hypertensive peristalsis" is defined as normally propagating peristalsis in the smooth muscle esophagus with a DCI between 5,000 and $8,000 \mathrm{mmHg} \cdot \mathrm{cm} \cdot \mathrm{sec}$ and normal IRP. It is akin to what was diagnosed by conventional manometry as nutcracker esophagus. These patients can have dysphagia and/or chest pain. All of these borderline esophageal motor abnormalities can be associated with GERD, so a treatment trial is reasonable. While these EPT patterns are not normal according to the classification scheme, they are relatively commonly seen in asymptomatic individuals. This raises questions about their clinical significance. In fact, the diagnosis of borderline esophageal motor function carries a very good prognosis, with little if any worsening symptoms or major therapeutic interventions 5 years after the initial manometric diagnosis. ${ }^{31}$

\section{What the Chicago Classification Does Not Tell Us?}

While the advent of HRM and the Chicago classification improved our ability to diagnose disorders of esophageal motor function, there are a number of motor problems not addressed by the classification. In 2011 at the Royal London Hospital Upper GI Physiology Unit, 32\% of patients undergoing high-resolution esophageal manometry had esophageal motor abnormalities not classifiable by the Chicago classification. ${ }^{32}$ Those abnormalities included things like disorders of the pharynx, UES or striated muscle esophagus, post-surgical problems and the rumination syndrome. Also, the Chicago classification was developed analyzing $5 \mathrm{~mL}$ wet swallows, so it cannot be applied to provocative testing with viscous or solid bolus swallows, or multiple repetitive wet swallows.

The pharynx, UES and proximal $5 \mathrm{~cm}$ of esophagus are composed of striated muscle. Evaluation of this region by conventional manometry was always problematic because wide sensor spacing made it difficult to track the UES and pharynx, which move relative to the catheter during swallowing. The analysis of high-resolution pressure topographic plots obtained in this region during swallowing is just beginning. ${ }^{33,34}$ Elevation of pharyngeal intrabolus pressure is easily identified with high-resolution pressure topographic plots (Fig. 12). When present it raises the possibility of pharyngeal outflow obstruction by a cricopharyngeal bar. ${ }^{16}$

HRM allows us to more reliably examine function of the UES. The most common UES abnormality is a hypertensive UES, which usually is an artifact resulting from irritation caused 


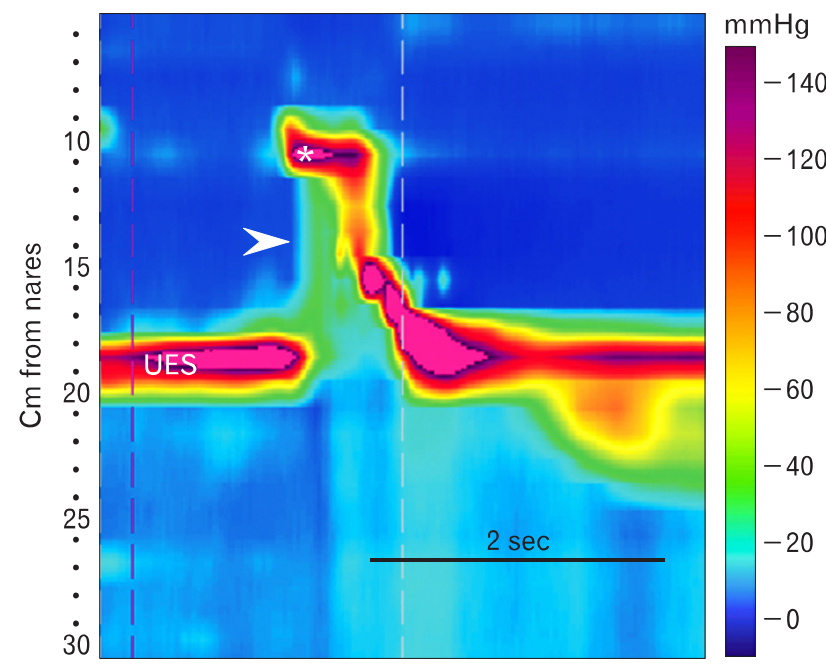

Figure 12. Pharyngeal pressurization. This is a topographical plot of pharyngeal motor function produced by a $5 \mathrm{~mL}$ water swallow. The asterisk indicates velopalatine closure. Above this is the nasopharynx. Between it and the upper esophageal sphincter (UES) is the mesopharynx. Pharyngeal peristalsis is seen as the pressure wave propagating from the end of velopalatine closure to the UES. Normally, during swallow-induced opening of the UES pharyngeal bolus pressure approximates that in esophageal bolus. In this case there is an elevated pharyngeal bolus pressure (arrowhead). This finding raises the possibility of pharyngeal outlet obstruction by a cricopharyngeal bar.

by catheter placement. This is often accompanied by prolonged, hypertensive peristaltic contractions of the striated muscle esophagus. These abnormalities tend to disappear over time, as the patient accommodates to the catheter. The UES is occasionally hypotensive. This abnormality often expresses itself as the study progresses, probably also because of accommodation to the catheter. The sometimes-striking changes in resting UES pressure as the study progresses suggest that UES evaluation might be more reliable at the study's end. A hypotensive UES is observed in patients with neuromuscular diseases that affect striated muscle, ${ }^{16,35,36}$ but may also be a part of the aging process. ${ }^{37}$ UES pressure usually varies during the respiratory cycle, increasing during inspiration. In about $60 \%$ of patients with globus sensation, these respiratory changes in UES pressure become greater than normal, producing what has been called the "hyperdynamic UES." ${ }^{38}$ The UES opens spontaneously in several situations: to vent the esophagus when bolus transit is compromised, as with achalasia, and during transient LES relaxation, rumination events or supragastric belches. ${ }^{16}$

Hypotensive or absent peristalsis in the striated muscle esophagus is seen with neuromuscular diseases that affect striated

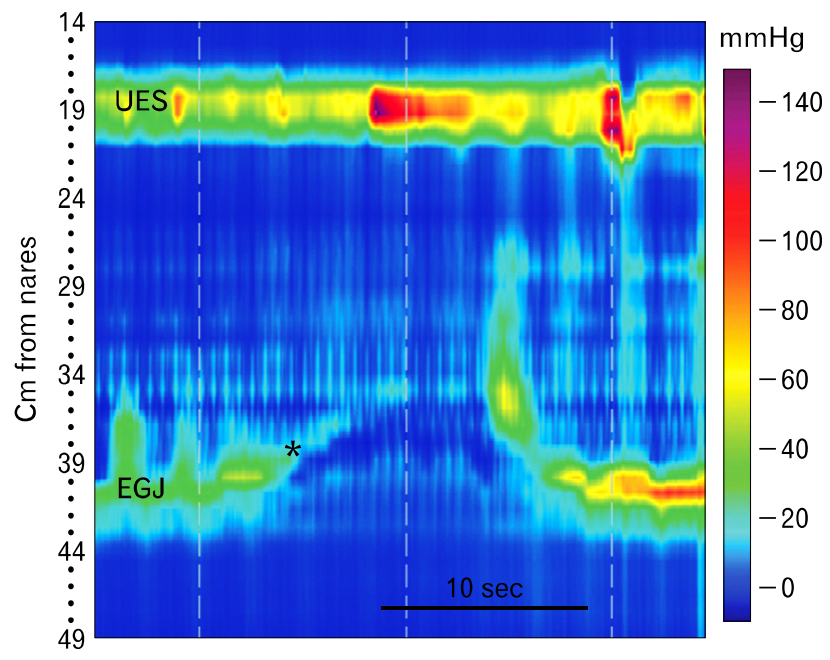

Figure 13. Transient lower esophageal sphincter (LES) relaxation is characterized manometrically by prolonged LES relaxation in the absence of a swallow, shortening of the esophagus (*), inhibition of crural diaphragm motor activity produced by respiration and equalization of the pressure across the esophagogastric junction upon its opening. Often there is opening of the upper esophageal sphincter to produce a belch, but not in this case. Ending of the transient LES relaxation is heralded by esophageal contraction, and the LES descends to its resting position. UES, upper esophageal sphincter; EGJ, esophagogastric junction.

muscle (e.g., myositis and myasthenia gravis, Parkinson disease) ${ }^{16,35,36,39}$ While the dogma is that these diseases affect only striated muscle, they frequently produce motor abnormalities of the smooth muscle esophagus. These abnormalities of smooth muscle esophageal function range from weak peristalsis to an achalasia pattern. The pathogenesis of these motor abnormalities is unknown. Radiation injury can also produce profound weakness of UES and striated muscle esophagus. ${ }^{16}$

Transient LES relaxation (tLESR), rumination and supragastric belch can be observed and differentiated with high-resolution esophageal manometry. ${ }^{40-42}$ We have known since the pioneering work of Dodds et al, ${ }^{43} 3$ decades ago that tLESR is a major cause of gastroesophageal reflux. Transient LES relaxations result from a vagovagal reflex that is activated by distention of the gastric cardia, and integrated in the nucleus tractus solitarious and dorsal motor nucleus of the vagus. ${ }^{44}$ They are characterized manometrically by prolonged LES relaxation in the absence of a swallow, shortening of the esophagus, inhibition of crural diaphragm motor activity produced by respiration and equalization of the pressure across the EGJ upon its opening (Fig. 13). On some occasions the UES opens transiently to produce what is 
now termed a "gastric belch." ${ }^{42}$ An esophageal after contraction often occurs as the tLESR ends and the LES resumes its resting position. Rumination syndrome is an apparently effortless, often repetitive regurgitation of recently ingested food into the mouth. It is characterized manometrically by a valsalva (contraction of the abdominal wall musculature), which increases intra-abdominal pressure, relaxation of the UES and retrograde movement of a pressure wave from the stomach up the esophagus (Fig. 14). One variation on this pattern is a rumination-like event that occurs during a tLESR. This has been called reflux related rumination. $^{41}$ Supragastric belches are characterized by downward movement (contraction) of the diaphragm, increased pressure at the EGJ and opening of the UES, which generate a negative intraesophageal pressure allowing antegrade flow of air into the esophagus. This is followed immediately by an increase in intraesophageal pressure and retrograde expulsion of air from the esophagus (Fig. 15). ${ }^{42}$ These patients often suffer from rapid-fire, repetitive air intake and belch that is visually striking.

HRM has found a role in the evaluation of patient with esophageal symptoms after operations like Nissen fundoplication, Heller myotomy and bariatric surgery. ${ }^{45}$ No attempt to ap-

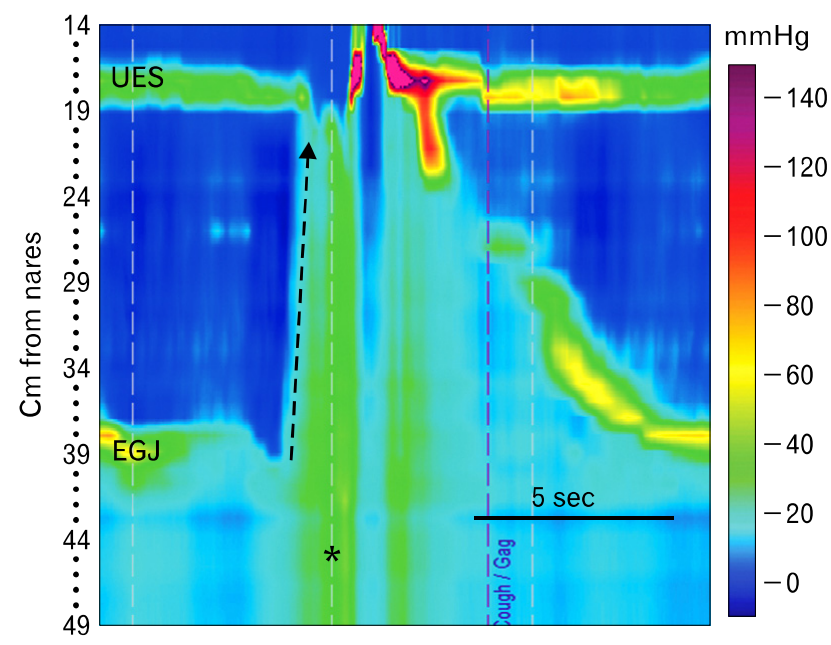

Figure 14. Rumination is characterized manometrically by a valsalvainduced increase in intragastric pressure (*), relaxation of the upper esophageal sphincter and retrograde movement of a pressure wave from the stomach up the esophagus (dashed arrow). In this case, a swallow follows the event. After performing a standard high-resolution manometry, the patient ate a meal he felt would produce symptoms. He was instructed to identify regurgitation events by pressing the gag/choke marker on the monitor screen, and was left with the catheter in place for 30 minutes. Here he marked a rumination event. UES, upper esophageal sphincter; EGJ, esophagogastric junction. ply the Chicago classification to these situations has been made yet. A tight fundoplication can be characterized by EPT patterns that look like outlet obstruction; e.g., elevated IRP and pressurization ahead of peristalsis. When the obstruction is left unattended, weak peristalsis or even patterns that look like achalasia can be seen. A dual high-pressure zone (HPZ) at the EGJ often characterizes failure of a Nissen fundoplication. ${ }^{46}$ This dual HPZ might represent herniation of the LES above the wrap and hiatus, or slippage of the wrap above the EGJ. These situations can be distinguished by identifying where the PIP is located relative to the other HPZ. Recurrent dysphagia after Heller myotomy can be caused by incomplete myotomy, scar at the EGJ, a tight partial fundoplication or megaesophagus. Manometric persistence of significant resting LES pressure following myotomy suggests an incomplete myotomy or tight wrap. In this situation, treatment with botulinum toxin or balloon dilation might be useful. Esophageal motor abnormalities do occur after bariatric surgery. This is especially true after the laparoscopic band, which produces some disordered esophageal motility in $70 \%$ of patients and an achalasia pattern in $5 \% .{ }^{47}$ This band-induced pseudoachalasia might not resolve with band deflation or removal.

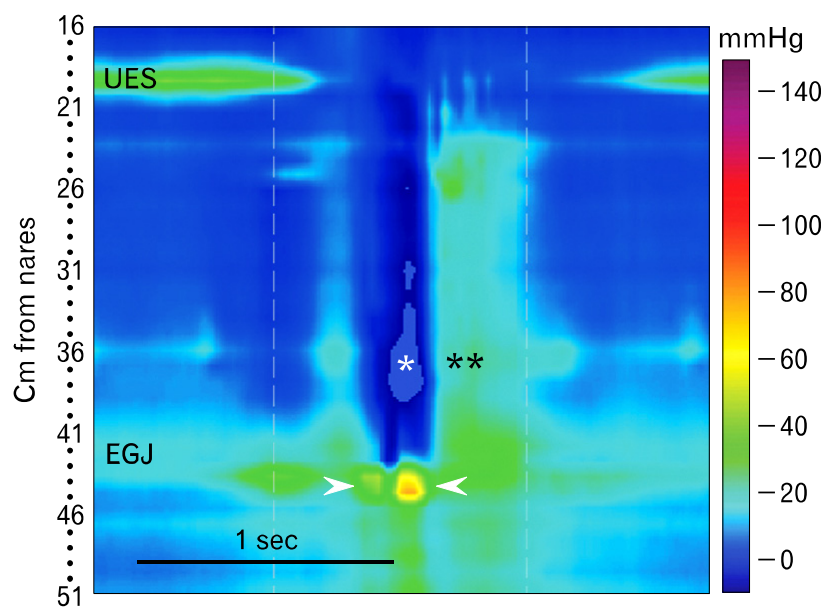

Figure 15. Supragastric belching is striking to observe, with the patient repetitively forcing air into the esophagus and then expelling it immediately. This single supragastric belch is identified manometrically as opening of the upper esophageal sphincter and simultaneous increase of pressure at the esophagogastric junction produced by diaphragmatic contraction (arrowheads). The associated lowering of intrathoracic pressure (*) allows entry of air into the esophagus, but does not allow it to enter the stomach. This is followed immediately by a pressure wave in the esophagus $(* *)$ that is associated with expulsion of gas. Once initiated the patient may repeat this behavior for some time. UES, upper esophageal sphincter; EGJ, esophagogastric junction. 


\section{Conclusions}

HRM has made esophageal manometry easier for the technician and more tolerable for the patient. It provides us with a complete spatial and temporal view of esophageal motor function for the first time. In fact, almost all disorders of esophageal motor function produce different EPT patterns that are easily recognized. Serious efforts to distinguish distinct esophageal motor disorders based on the EPT led to the development of the Chicago classification, which remains a work in progress, and is not applicable to all esophageal motor disturbances like pharyngeal dysfunction, rumination and supragastric belches. It has not yet been applied to methods that challenge the esophagus like multiple rapid swallows, viscous swallows or solid swallows. Future work in this area, combining the Chicago classification system with challenge techniques, should improve our diagnosis and understanding of esophageal dysfunction.

\section{References}

1. Steff JJ, Dodds WJ, Hogan WJ, Linehan JH, Stewart ET. Intraluminal esophageal manometry: an analysis of variables affecting recording fidelity of peristaltic pressures. Gastroenterology 1974; 67:221-230.

2. Arndorfer RC, Steff JJ, Dodds WJ, Linehan JH, Hogan WJ. Improved infusion system for intraluminal esophageal manometry. Gastroenterology 1977;73:23-27.

3. Clouse RE, Staiano A. Topography of the esophageal peristaltic pressure wave. Am J Physiol 1991;261(4 Pt 1):G677-G684.

4. Clouse RE, Staiano A, Alrakawi A, Harolan A. Application of topographical methods to clinical esophageal manometry. Am J Gastroenterol 2000;95:2720-2730.

5. Murray JA, Clouse RE, Conklin JL. Components of the standard oesophageal manometry. Neurogastroenterol Motil 2003;15:591-606.

6. Pandolfino JE, Kahrilas PJ, American Gastroenterological Association. AGA technical review on the clinical use of esophageal manometry. Gastroenterology 2005;128:209-224.

7. Bredenoord AJ, Fox M, Kahrilas PJ, et al. Chicago classification criteria of esophageal motility disorders defined in high resolution esophageal pressure topography. Neurogastroenterol Motil 2012;24 (suppl 1):57-65.

8. Sifrim D, Janssens J, Vantrappen G. A wave of inhibition precedes primary peristaltic contractions in the human esophagus. Gastroenterology 1992;103:876-882.

9. Sweis R, Anggiansah A, Wong T, Fox M. Normative values and inter-observer agreement for liquid and solid bolus swallows in upright and supine positions as assessed by esophageal high-resolution manometry. Neurogastroenterol Motil 2011;23:509-e198.

10. Xiao $\mathrm{Y}$, Read A, Nicodème F, Roman S, Kahrilas PJ, Pandolfino JE. The effect of a sitting vs supine posture on normative esophageal pres- sure topography metrics and Chicago Classification diagnosis of esophageal motility disorders. Neurogastroenterol Motil 2012;24:e509-e516.

11. Basseri B, Pimentel M, Shaye O, Low K, Soffer EE, Conklin JL. Apple sauce improves detection of esophageal motor dysfunction during high-resolution manometry evaluation of dysphagia. Dig Dis Sci 2011;56:1723-1728.

12. Sweis R, Anggiansah A, Anggiansah R, Fong J, Wong T, Fox M. Inclusion of solid swallows and a test meal increase the diagnostic yield of high-resolution manometry (HRM) in patients with dysphagia [abstract]. Gastroenterology 2011;140:S-77.

13. Savojardo D, Mangano M, Cantù $\mathrm{P}$, Penagini R. Multiple rapid swallowing in idiopathic achalasia: evidence for patients' heterogeneity. Neurogastroenterol Motil 2007;19:263-269.

14. Sweis R, Anggiansah R, Wong T, Anggiansah A, Fox M. High resolution manometry with large volume multiple repeated swallows aids the detection of esophageal pathology. [abstract]. Gastroenterology 2008;134:A719.

15. Fornari F, Bravi I, Penagini R, Tack J, Sifrim D. Multiple rapid swallowing: a complementary test during standard oesophageal manometry. Neurogastroenterol Motil 2009;21:718-e41.

16. Conklin JL, Pimentel M, Soffer E. A color atlas of high-resolution manometry. New York: Springer 2009.

17. Ghosh SK, Pandolfino JE, Rice J, Clarke JO, Kwiatek M, Kahrilas PJ. Impaired deglutitive EGJ relaxation in clinical esophageal manometry: a quantitative analysis of 400 patients and 75 controls. Am J Physiol Gastrointest Liver Physiol 2007;293:G878-G885.

18. Pandolfino JE, Leslie E, Luger D, Mitchell B, Kwiatek MA, Kahrilas, PJ. The contractile deceleration point: an important physiological landmark on oesophageal pressure topography. Neurogastrenterol Motil 2010;22:395-400.

19. Roman S, Lin Z, Pandolfino JE, Kahrilas PJ. Distal contraction latency: a measure of propagation velocity optimized for esophageal pressure topography studies. Am J Gastroenterol 2011;106:443- 451.

20. Behar J, Biancani P. Pathogenesis of simultaneous esophageal contractions in patients with motility disorders. Gastroenterology 1993;105:111-118.

21. Murray J, Ledlow A, Launspach, J, Evans D, Loveday M, Conklin $\mathrm{JL}$. The effects of recombinant human hemoglobin on esophageal motor function in humans. Gastroenterology 1995;109:1241-1248.

22. Pandolfino JE, Roman S, Carlson D, et al. Distal esophageal spasm in high-resolution esophageal pressure topography: defining clinical phenotypes. Gastroenterology 2011;141:469-475.

23. Pandolfino JE, Ghosh SK, Rice J, Clarke JO, Kwiatek MA, Kahrilas PJ. Classifying esophageal motility by pressure topography characteristics: a study of 400 patients and 75 controls. Am J Gastroenterol 2008;103:27-37.

24. Pandolfino JE, Kwiatek MA, Nealis T, Bulsiewicz W, Post J, Kahrilas PJ. Achalasia: a new clinically relevant classification by high-resolution manometry. Gastroenterology 2008;135:1526-1533.

25. Jee SR, Pimentel M, Soffer E, Conklin JL. A high-resolution view of achalasia. J Clin Gastroenterol 2009;34:644-651.

26. Salvador R, Costantini M, Zaninotto G, et al. The preoperative manometric pattern predicts the outcome of surgical treatment for esophageal achalasia. J Gastrointest Surg 2010;14:1635-1645.

27. Scherer JR, Kwiatek MA, Soper NJ, Pandolfino JE, Kahrilas PJ. Functional esophagogastric junction obstruction with intact peristalsis: a heterogeneous syndrome sometimes akin to achalasia. J 
Gastrointest Surg 2009;13:2219-2225.

28. Gyawali CP, Kushnir VM. High-resolution manometric characteristics help differentiate types of distal esophageal obstruction in patients with peristalsis. Neurogastroenterol Motil 2011;23:502-e197.

29. Gyawali CP, Bredenoord AJ, Conklin JL, et al. Evaluation of esophageal motor function in clinical practice. Neurogastroenterol Motil 2013;25:99-133.

30. Ghosh SK, Janiak P, Fox M, Schwizer W, Hebbard GS, Brasseur JG. Physiology of the oesophageal transition zone in the presence of chronic bolus retention: studies using concurrent high-resolution manometry and digital fluoroscopy. Neurogastroenterol Motil 2008; 20:750-759.

31. Ravi K, Friesen L, Issaka RB, Kahrilas PJ, Pandolfino JE. The natural history of patients with normal and borderline motor function on high-resolution manometry. Gastroenterology 2012;12(suppl 1):S34.

32. Wan UT, Yazaki E, Sifrim D. High-resolution manometry: esophageal disorders not addressed by the Chicago classification. J Neurogastroenterol Motil 2012;18:365-372.

33. Mielens JD, Hoffman MR, Ciucci MR, Jiang JJ, McCulloch TM. Automated analysis of pharyngeal pressure data obtained with highresolution manometry. Dysphagia 2011;26:3-12.

34. Geng Z, Hoffman MR, Jones CA, McCulloch TM, Jiang JJ. Three-dimensional analysis of pharyngeal high-resolution manometry data. Laryngoscope Published Online First: 16 Feb 2013. doi: 10.1002/lary.23987.

35. Ebert EC. Review article: the gastrointestinal complications of myositis. Aliment Pharmacol Ther 2010;31:359-365.

36. Huang MH, King KL, Chien KY. Esophageal manometric studies in patients with myasthenia gravis. J Thorac Cardiovasc Surg 1988; 95:281-285.

37. Fulp SR, Dalton CB, Castell JA, Castell DO. Aging-related alterations in human upper esophageal sphincter function. Am J Gastroenterol 1990;85:1569-1572.

38. Kwiatek MA, Mirza F, Kahrilas PJ, Pandolfino JE. Hyperdynamic up- per esophageal sphincter pressure: a manometric observation in patients reporting globus sensation. Am J Gastroenterol 2009;104:289-298.

39. Leopold NA, Kagel MC. Pharyngo-esophageal dysphagia in Parkinson's disease. Dysphagia 1997;12:11-18.

40. Pandolfino JE, Zhang QG, Ghosh SK, Han A, Boniquit C, Kahrilas PJ. Transient lower esophageal sphincter relaxations and reflux: mechanistic analysis using concurrent fluoroscopy and high-resolution manometry. Gastroenterology 2006;131:1725-1733.

41. Tucker E, Knowles K, Wright J, Fox MR. Rumination variations: aetiology and classification of abnormal behavioural responses to digestive symptoms based on high-resolution manometry studies. Aliment Pharmacol Ther 2013;37:263-274.

42. Kessing BF, Bredenoord AJ, Smout AJ. Mechanisms of gastric and supragastric belching: a study using concurrent high-resolution manometry and impedance monitoring. Neurogastroenterol Motil 2012; 24:e573-e579.

43. Dodds WJ, Dent J, Hogan WJ, et al. Mechanisms of gastroesophageal reflux in patients with reflux esophagitis. N Engl J Med 1982;307:1547-1552.

44. Wise JL, Conklin JL. Gastroesophageal reflux disease and baclofen: is there a light at the end of the tunnel? Curr Gastroenterol Rep 2004;7:213-219.

45. Burch M, Conklin JL. Post-surgical dysphagia: post-nissen fundoplication, C-spine surgery, thyroid surgery, gastric banding, gastric bypass. In: Shaker R, Belafsky P, Postma G, Easterling C, eds. Principles of deglutition: a multidisciplinary text for swallowing and its disorders. New York: Springer 2012:631-644.

46. Tatum RP, Soares RV, Figueredo E, Oelschlager BK, Pellegrini CA. High-resolution manometry in evaluation of factors responsible for fundoplication failure. J Am Coll Surg 2010;210:611-617.

47. Naef M, Mouton W, Naef U, van der Weg B, Maddern GJ, Wagner HE. Esophageal dysmotility disorders after laparoscopic gastric banding - an underestimated complication. Ann Surg 2011; 253:285-290. 